\title{
ARTIGO
}

Sociologias, Porto Alegre, ano 10, no 20, jun./dez. 2008, p. 270-290

\section{La región de la triple frontera: territorios de integración y desintegración}

RAMÓN FOGEL*

\section{Resumen}

En el articulo se analiza la triple frontera (Foz de Iguazú, Puerto Iguazu e Ciudad del Elste) como territorio construido, apropriado y controlado por actores, algunos extra regionales. Estos actores mantienen vínculos entre si que implican relaciones de poder, y están involucrados en actividades y procesos con incidencia en la integración regional.

Palabras clave: Triple frontera. Territorio. Integración regional.

\section{Alcance del artículo}

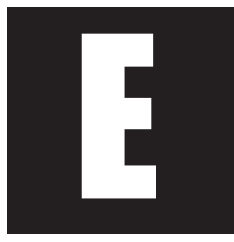

n este artículo la frontera es pensada como una región. La región de fronteras en este planteo está constituido por múltiples relaciones (económicas, sociales, políticas, laborales, culturales, personales, etc.) entre actores de diversa naturaleza, que configuran un espacio transnacional; este espacio está marcado por contrastes entre los países que comparten la frontera y al interior de sus regiones. Las asimetrías más notables son la pobreza y la desigualdad. La construcción y control del territorio, con sus actividades y procesos, en ese espacio implican relaciones de poder entre

\footnotetext{
* Investigador del Centro de Estudios Rurales Interdisciplinarios (CERI-UNA, Paraguay) 1 Ponencia presentada en el II Seminario Internacional de Estudios Regionales Sudamericanos: contrastes socio-territoriales y perspectivas de integración regional.Cuiabá. 2006.
} 
los actores involucrados, algunos extra regionales; en el análisis se enfatizan las actividades y procesos que facilitan la integración de los países incluidos en la frontera, como aquellas que la dificultan, considerando el entorno externo.

\section{Los rasgos básicos de la región}

La región de Tres fronteras, que al mismo tiempo une y separa a Brasil, Paraguay y Argentina, está modelada por los ríos Yguazú y Paraná, que recoge las aguas de aquél, y forma el embalse del lago de la represa de Itaipú de 1350 km² (Sader, 2006), y tiene como centro la ciudades de Foz de Yguazu, Ciudad del Este y Puerto Yguazu; la represa de Itaipú representa un buen ejemplo de complementación energética, una de las áreas claves de la integración.

Geográficamente la región se encuentra en el epicentro del sistema hídrico del acuífero Guaraní, uno de los más grandes del planeta, y el primero en cuanto a facilidad de acceso. Esa posición geográfica hace de las Tres fronteras un punto importante para el control del territorio del continente (Sader, 2006; Ceceña, 2005).

La población del territorio pasó de 60.000 habitantes al comienzo de la construcción de la represa de Itaipú, en 1970, a 700.000 habitantes en el 2001 (Sader, 2006). En el lado paraguayo, Ciudad del Este cuenta con 223.000 habitantes, mientras los otros municipios del Departamento de Alto Paraná que se encuentran en el área de influencia directa del lago de Itaipú totalizan 340.000 habitantes. La actividad comercial entre Foz de Yguazu y Ciudad del

Este constituye un mercado de trabajo transfronterizo tan importante que en los días pico pasan a Ciudad del Este unos 30.000 sacoleiros brasileños. La intensa actividad comercial en Ciudad del Este - en buena parte ilegal explica la presencia de 6.000 habitantes pertenecientes a la religión islámica, migrantes árabes o de países musulmanes no árabes. 
El comercio de Ciudad del Este depende de ese ir y venir a través de la frontera, que involucra a miles de paseros diariamente. En el dinámico territorio transfronterizo se desarrolla una trama densa de relaciones entre actores sociales y políticos, locales, nacionales y transnacionales (Albínzano, 2004a). La región, mirada desde el lado paraguayo, comprende un proceso intenso de reconfiguración del territorio, impulsado por la expansión de la producción de soja transgénica, en una suerte de prolongación de la dinámica brasileña.

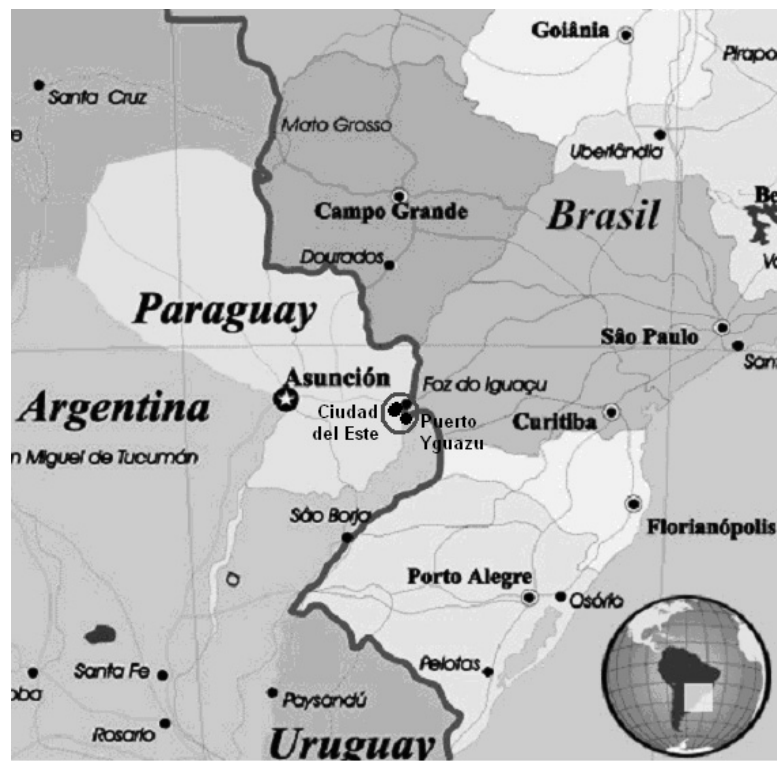

Figura 1.

Algunos procesos relevantes y la apropiación del territorio

Diversos son los procesos que se desarrollan en la región, que experimenta intensos cambios sociales, algunos favorecen la integración regional y deberían ser potenciados, mientras otros la obstaculizan, y deberían 
ser controlados; algunas de estas prácticas que involucran a diversos actores son contradictorios, en tanto tienen aspectos negativos para la integración así como aspectos positivos --.o por lo menos potencialmente positivosde cara a esa integración. No obstante lo anotado pueden diferenciarse actividades y procesos que básicamente obstaculizan la integración en cuestión, y que vistos desde el Paraguay, comprenden:

- $\quad$ Contrabando (de droga, de armas, de otros bienes)

- $\quad$ Expansión de la producción de sojeros brasileños que operan en un régimen de enclave

- Control de la biodiversidad por actores extra regionales

- Control y hostigamiento de la comunidad islámica por actores extraregionales.

Los aspectos potencialmente positivos que deben potenciarse, a su vez comprenden:

- $\quad$ Actividad comercial que incluye a la colectividad islámica de Ciudad del Este

- $\quad$ Operación de la represa hidroeléctrica de Itaipú, la más grande del mundo

- $\quad$ Estudios del Acuífero Guaraní, encarados por el Banco Mundial.

Desde el punto de vista de la construcción del territorio, la Región de la Triple Frontera es un espacio apropiado, ocupado y dominado por determinados actores, para satisfacer sus necesidades materiales y simbólicas; dado que la región tiene recursos escasos, su apropiación supone relaciones de poder. En esa apropiación del espacio se relacionan su alcance utilitario y simbólico expresivo, en tanto los aspectos materiales y culturales del territorio están estrechamente asociados (Giménez y Héau,2007); el análisis de estos aspectos será enfatizado en las proposiciones que siguen.

Históricamente la apropiación de la región fue practicada a través de la agricultura de roza por los Guaraní, que conservaron sus nichos en la 
época de los enclaves que explotaron yerba mate y madera, hasta mediados del siglo pasado. Desde el punto de vista simbólico el territorio fue apropiado por los indígenas Guaraní como tekoha, lugar donde se reproduce la cultura. Para estos poblaciones autóctonas los aspectos utilitarios y culturales difícilmente se diferencian, hasta el punto que las especies forestales están estrechamente asociados a los héroes culturales de la etnia. En su sistema de creencias la palabra verdadera, que refleja el alma (ñe'e) brota del cedro o yvyra ñeery una de las especies forestales mas valoradas por estos nativos. La agricultura misma está estrechamente asociada a rituales religiosos en los que se recuerdan las normas de la vida comunitaria asociadas a la reciprocidad y a la solidaridad.

Aun cuando desde la época colonial los grupos dominantes miraban a los indígenas con una visión prejuiciada que conducía a la negación de los derechos territoriales de los indígenas, éstos pudieron conservar sus nichos durante la época de los obrajes que explotaban madera y yerba mate; estos extensos obrajes eran operados por agentes del capital internacional, que siempre fueron exaltados por los grupos políticamente dominantes del país, aunque inauguraran en el país la dinámica de enclaves; en los hechos la apropiación territorial de los indígenas no afectaba las practicas de los obrajes.

El propio Estado había vendido a fines del siglo XIX enormes extensiones de tierras públicas de la región a agentes del capital internacional; las clases y grupos dominantes entonces se imaginaban que con la entrega de esas tierras vendrían la civilización y el desarrollo, y para facilitar aquella utopía dictó las leyes de vagos para posibilitar el enganche forzoso de peones y la de carta blanca permitiendo el monopolio de la fuerza por parte de los que operaban los extensos obrajes.

A partir de la década de 1960 cuando declinaron los grandes obrajes ligados al capital internacional, que controlaron toda la región, se establecieron en la región colonias con campesinos paraguayos, promovidas por el Estado que había recuperado parte de las tierras de la región que quedaron disponibles con el agotamiento del ciclo de los obrajes; los campesinos 
colonos se representaban la región como una oportunidad para acceder a una parcela que le permitiera sobrevivir, dado que provenían de, minifundios pulverizados de la región central, y al apropiarse del territorio lo primero que hicieron fue desbrozar el terreno como pioneros en la frontera.

Luego el territorio fue progresivamente apropiado, a partir de la década de 1970 por colonos brasileños que ocuparon primero los espacios libres, y luego comenzaron a desplazar a los colonos paraguayos; en la representación de la región por parte de los colonos brasileños también pioneros de la frontera la región tenia un gran potencial para la producción agrícola para el mercado internacional, incluyendo la soja, y en el repliegue de los campesinos paraguayos pudo apreciarse debilidades en su sentido de pertenencia, en la medida que aparecían discriminados en su propio país, aunque de todos modos en su cultura pervivían rasgos de la identidad nacional, más que la regional o local.

En la medida que las representaciones orientan las prácticas sociales la inclinación a replegarse inicialmente de los campesinos paraguayos se altera luego, cuando ya va quedando poca tierra cultivable por ellos en la región, y se altera la lógica prevaleciente de expansión de la colonización brasileña y repliegue de la población campesina criolla.

La expansión de Ciudad del Este, particularmente notable en la década de 1980 va asociada a la apropiación del espacio del centro comercial de la ciudad por parte de más de una veintena de colectividades etnoculturales de inmigrantes, la mayoría de ellos musulmanes.

\section{La actividad comercial y el contrabando. Integración e ilegalidad}

El contrabando tuvo su apogeo bajo la dictadura de Stroessner, y actualmente es facilitado por el inmenso lago de Itaipú, de $1350 \mathrm{~km}^{2}$, que ensancha la frontera. Además del tráfico de armas, de drogas, incluyendo sus subproductos, contrabando de productos electrónicos. Inicialmente el 
contrabando fue de whisky y cigarrillos en gran escala, transformándose en una suerte de turismo de compra que involucran a miles de sacoleiros y de vendedores callejeros de Ciudad del Este, que no encuentran empleo en el mercado formal de trabajo.

Desde el punto de vista de la construcción social del territorio la multiculturalidad es el rasgo central. Ciudad del Este es un caso de apropiación y construcción del territorio por parte de inmigrantes de más de veinte nacionalidades, la mayoría de los cuales se instalaron en la ciudad como pioneros, y cada colectividad mantiene su propio nicho sin colisionar con otros. Este sector comercial es el que mantiene relaciones de interdependencia con los turistas y sacoleiros brasileños, en el centro comercial más importante del continente luego de Miami.

El carácter contradictorio de la situación se expresa en la integración entre sacoleiros de Foz de Yguazú y comerciantes de Ciudad de Ciudad del Este, y el conflicto con la lógica de la Reserva Federal; sacoleiros y comerciantes callejeros de Ciudad del Este mitigan la creciente exclusión de mercados formales de trabajo con una suerte de complementación, mientras las barreras aduaneras se convierte en una fuente de problemas que distancian a los gobiernos.

En efecto, desde el mes de Octubre del 2006 se desarrolla un control conjunto entre unos 40 fiscalizadores de la Receita Federal, dos pelotones del ejército brasileño y policías; este operativo busca desalentar la venida de compradores a Ciudad del Este y reprimir el contrabando en la frontera con Paraguay. Las incautaciones de este año 2006, con un valor que se aproximan a los 150 millones de Reales, dan una idea de la magnitud del movimiento comercial froterizo ${ }^{2}$. Todo parece indicar que los controles del lado brasileño se endurecerán a partir de un nuevo complejo aduanero, que requerirá por lo menos 200 operadores $^{3}$. 
Puede esperarse que con las medidas de represión referidas disminuirá el ingreso de contrabando hormiga desde Ciudad del Este, demostrando que el escenario comercial no es promisorio para la integración en la región, aunque la experiencia reciente demostró las posibilidades de un mercado fronterizo de trabajo informal, como respuesta a un desarrollo capitalista que excluye crecientemente de los mercados formales de trabajo.

\section{El control territorial por parte de sojeros brasileños y conflictos etnoculturales}

A diferencia de la actividad comercial de las Tres Fronteras que constituye un mercado de trabajo transfronterizo que integra a paraguayos y brasileños, la expansión de los sojeros brasileños en la región de Alto Paraná y Canindeyú es causa de conflictos crecientes; los excesos del modelo sin embargo impulsaron la agregación de fuerzas entre sectores campesinos de los tres países. Este proceso de expansión de la soja transgénica va desplazando a campesinos paraguayos empobrecidos de las colonias nacionales, que migran crecientemente a Ciudad del Este y otros centros urbanos, donde no tienen las posibilidades de ocupación que les brindaban sus parcelas.

En este caso el contraste al interior de la región, en el lado paraguayo, se proyecta en la diferenciación socio-económica, entre campesinos paraguayos pobres y empresarios brasileños prósperos, que coincide con la diferenciación etnocultural. En cuanto a la intensidad de esta expansión debe tenerse en cuenta que a nivel mundial la tasa de expansión es de $3,3 \%$ anual, similar a la del Brasil, mientras en el Paraguay la expansión del área cultivada es superior al 8,5\% anual, y se da básicamente a costa de la economía campesina.

La irrupción de este cultivo extensivo, en las colonias nacionales, conlleva la expulsión de familias campesinas, y conflictos por el uso indiscriminado de agrotóxicos. En el caso de las comunidades indígenas las 
consecuencias son igualmente negativas, destacándose la descomposición de la organización social de las comunidades, que se ve alimentada en esas colonias por la corrupción —inducida por los sojeros - de los líderes, y sectores de los asentamientos indígenas, que se benefician con el arriendo ilegal de tierras. Este arriendo de tierras no parte de la cultura indígena y está prohibida está previsto por leyes vigentes.

La representación de la región como espacio con gran potencial para la soja se corresponde con la apropiación efectiva del territorio con el cultivo de la soja transgénica, hasta convertir los departamentos fronterizos en desiertos de soja. Mientras la expansión se dio en espacios libres y los campesinos paraguayos tuvieron opción a otras tierras, ellos se desplazaron apelando a su orientación al repliegue, que corresponde a las formas como los grupos dominantes se representan a la región. Una vez que se acabaron las tierras disponibles en cambio se altera esa dinámica de expansión de sojeros brasileños y repliegue de campesinos paraguayos, y en la identidad de los campesinos paraguayos resalta su carácter de guarání parlantes y portadores de esa cultura criolla, mientras se movilizan en la recuperación de por lo menos parte de su territorio.

Esta expansión del cultivo en Alto Paraná tiene rasgos peculiares, ya que se trata de una región pionera en la producción de soja, donde las posibilidades de expansión de la frontera de la soja son ya limitadas; seis años atrás ya la superficie sembrada con la oleaginosa había superado las 390.000 has. Canindejú es el otro departamento de la región y tiene tasas de expansión mucho más altas que Alto Paraná.

Los departamentos con mayor producción de soja de la franja oriental son los que más brasileños y brasiguayos tienen, estimándose que residen en Alto Paraná entre 300.000 y 350.000, de 60.000 a 80.000 en Canindejú, de 30.000 a 40.000 en Amambay, y de 5.000 a 10.000 en Itapua y Concepción (Souchaud, 2002). Los campesinos paraguayos expulsados por 
la soja se desplazan a distritos con suelos pobres en el mismo departamento, donde se intensifica el empobrecimiento; pongamos por caso el distrito de Caballero Alvarez del Departamento Canindejú, con colonias agrícolas establecidas sobre buenos suelos es un área de éxodo, con tasas negativas del $12 \%$ anual acumulativo, mientras Curuguaty del mismo departamento, con suelos muy pobres crece a una tasa anual acumulativa del $9 \%$ y la incidencia de la pobreza extrema ya llega al 39 \% de los hogares. Se trata de un proceso, en la Región

De las Tres Fronteras, que acentúa la pobreza extrema y la desigualdad; la asimetría entre los países se proyecta en la asimetría dentro del país; ciertamente aumenta la segmentación.

La brasileñización de la frontera, y sobre todo el control de las explotaciones grandes por empresarios brasileños era ya visible, en Alto Paraná y Canindejú, a principios de la década pasada; en Canindejú los propietarios de 5.000 has y más eran ausentistas, residentes en el Brasil (Fogel, 2001).

En el análisis de los efectos de la expansión de la soja transgénica en la región de la triple frontera resulta pertinente puntualizar que no se trata simplemente de la producción de una oleaginosa, sino más bien del conjunto de relaciones socioeconómicas asociadas a un modelo productivo, que responde a las características de un enclave agroexportador que bloquea todo desarrollo de base amplia, que se basa en un paquete tecnológico que incluye el uso intensivo de agrotóxicos incluyendo desecantes, que originan conflictos con comunidades campesinas; este sistema se expande en colonias nacionales soslayando normas legales de diverso orden.

La mayor parte del cultivo es de semilla transgénica resistente al herbicida Roundup (glifosato), patentado por la Monsanto, que sumado a otros insumos constituye el paquete tecnológico que genera dependencia de los propios empresarios rurales que pasan a depender de las 
multinacionales que van controlando el mercado de semillas y de sus componentes tecnológicos, y en esa medida deciden qué, cómo, y para quién producir $^{4}$.

El poder creciente de los colosos de la biotecnología, que tienden más a la maximización de sus rentas que a las consecuencias sociales y ambientales de las tecnologías que venden, ha impulsado la agregación de fuerzas de organizaciones campesinas de Brasil, Paraguay y Argentina. En este caso la asociatividad a través de las fronteras es impulsada por la realidad económica y política mundial, por la competencia monopólica de las grandes corporaciones apoyada por la política exterior norteamericana.

La resistencia contra a este modelo genera sucesivos encuentros alternativos y movilizaciones que unen a actores subalternos de los tres países de la región, y da un alcance transnacional a las luchas contra un modelo productivo, que en una primera fase, hasta comienzos de esta década enfrentó en la región a sojeros brasileños y campesinos paraguayos, en conflictos que quedaron confinados al plano local. La expansión de la semilla transgénica de la colosal Monsanto, y el uso masivo de desecantes provoca el cambio de los enfrentados en el conflicto, que une ahora a los campesinos de los países de la región contra el modelo productivo, y las grandes corporaciones que lo articulan.

\section{Los estudios del Sistema Acuífero Guaraní}

Otra cuestión que otorga importancia estratégica a la Región de Tres Fronteras es el Sistema Acuífero Guaraní (SAG), el yacimiento subterráneo de agua dulce de mayor volumen del planeta, abarcando aproximadamente $1.195 .700 \mathrm{Km}^{2}$, de la cual se encuentra bajo suelo brasileños el 70\%, mientras el 19\% se encuentra bajo suelo argentino y el 6\% en Paraguay; el remanente,

4 Téngase en cuenta que los principales cultivos transgénicos son la soja, con 41,4 millones de has. en el 2003, el maíz con 15,5 millones de has, representando el 11 \% del total, el algodón con 7,2 millones de has, y la colza con 3,6 millones de has. Véase Boletín № 29. Red Rural. 2004. 
el 5\% se encuentra bajo suelo uruguayo. La importancia de estos países en el sistema sin embargo varía considerando el área de recarga del acuífero, ya que aproximadamente la mitad se encuentra en territorio paraguayo.

En la dinámica del acuífero la recarga natural se da a través de la infiltración directa de las aguas de lluvia y de forma indirecta por infiltración vertical. La calidad del agua de la recarga natural, sin embargo, puede verse afectada por el uso de agrotóxicos en grandes volúmenes sobre suelos con flujos subterráneos poco profundos, como los que se dan en los departamentos de Caaguazú y San Pedro, de Paraguay ${ }^{5}$. El sistema conforma un flujo subterráneo desde poco profundos a muy profundos, constituyendo un sistema conformado por formaciones geológicas permeables que alojan al agua subterránea y le permiten movilidad.

Debe notarse que el agua subterránea no reconoce fronteras políticas ya que el agua subterránea, alimentada en una cuenca hidrográfica atraviesa las fronteras del país y es explotada en otro país. Esto aumenta la necesidad de un manejo ambiental sustentable, ya que se trata de un acuífero que pertenece a cuencas hidrográficas compartidas.

Las reservas de agua o capacidad de almacenamiento del acuífero se estima en $40.000 \mathrm{Km}^{2}$, estimándose que estas reservas pueden satisfacer las demandas de 360.000.000 de personas a lo largo de 100 años, agotando solo el 10\% de su capacidad total (ANA 2003, citado por Ceceña y Motto, 2005).

En el análisis de la importancia del acuífero debe tenerse en cuenta que mucho menos del $1 \%$ del agua del planeta es apta para el consumo humano y animal, incluyendo el agua en forma de hielo en los polos glaciares, de difícil explotación con las tecnologías y costos actuales. La crisis del agua es de tal magnitud, que según las Naciones Unidas, existen actualmente 1,3 billones de personas en el mundo sin acceso a agua limpia; por otra parte 31 países se consideran localizados en áreas de escasez de agua. Se estima que la demanda mundial de agua se duplica cada 20 años, dos veces más rápido

5 Vale decir, el agua subterránea está integrada al ciclo hidrológico natural a través de la recarga por infiltración de las precipitaciones de áreas lejanas o cercanas. 
que el incremento de la población., y en el año 2025, según las previsiones, la demanda de agua fresca será de un 56 por ciento más que el suministro. ${ }^{6}$

Debe tenerse en cuenta también que la calidad del agua es tan importante como su cantidad, dado que el aumento de la contaminación en ciertas áreas, hace que disminuya la cantidad de agua utilizable; como resultado de esa contaminación, hoy más de cinco millones de personas mueren anualmente por enfermedades relacionadas con el agua, es decir diez veces más que la cantidad de muertos a causa de guerras en el mundo.

En ese contexto de creciente demanda mundial y relativa escasez de agua el acceso y control de este acuífero es de importancia estratégica indudable, (Ceceña y Motto, 2005), no solo para los países bajo cuyo suelo se encuentra este recurso, sino para actores extraterritoriales. El alcance político del recurso deriva del hecho que su control y/o posesión del agua, interesa a todos los paraguayos y a los ciudadanos de los países a los cuales subyace el acuífero. Una manera de prefigurarnos los conflictos potenciales sobre el manejo del acuífero es prestando atención a los problemas observados recientemente con el uso del agua. Algunos analistas indican, que el agua, junto al petróleo, se constituyen en centro de conflictos globales en las últimas décadas, y en esa medida puede suponerse que las grandes corporaciones apoyadas por los países ricos prestan atención al acuífero, al cual puedan echar mano y explotarlo.

\section{Mapa del Acuífero Guaraní en la Cuenca hidrográfica del Plata}

El conflicto potencial enfrenta por lo menos dos visiones diferenciadas, por un parte la visión del acuífero como un recurso ambiental común, compartido por cuatro países, ligado al derecho a la vida, y por otra la concepción del acuífero 


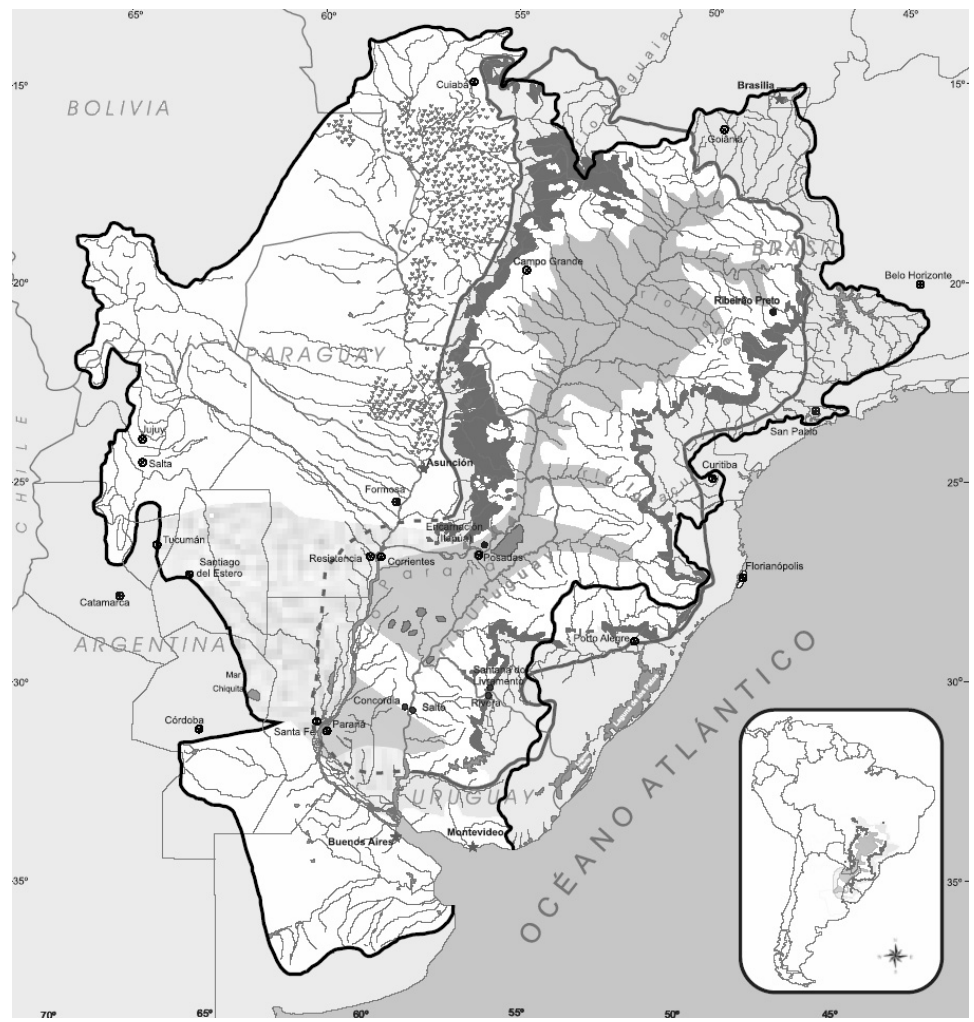

\section{Referencias:}

Áreas potenciales de recarga directa

Áreas potenciales de descarga

Áreas que cubre el Sistema Acuífero Guaraní

$\sim$ Límite de la Cuenca Hidrográfica del Plata

Fuente: http://www.sg-guaraní.org agotando solo el $10 \%$ de su capacidad total (ANA 2003, citado por Ceceña y Motto, 2005). 
como un recurso estratégico con valor económico que debería ser privatizado. Teniendo en cuenta los antecedentes referidos no resulta sorprendente el interés del Banco Mundial y del Global Environment Facilities (GEF) -cuyos recursos parcialmente lo maneja aquel_ y más bien resulta sintomático, ya que se trata de dos organismos estrechamente asociados a los intereses de las grandes corporaciones, o por lo menos tienen discursos coincidentes sobre la necesidad de privatización de recursos ambientales.

Lo concreto y fuera de toda duda es que el Banco Mundial actualmente implementa un proyecto que busca lograr la gestión y uso sostenible del Sistema Acuífero Guaraní (SAG); proponiéndose el proyecto apoyar a los 4 países a los cuales subyace el acuífero, para conjuntamente elaborar e implementar un marco común institucional, legal y técnico para manejar y preservar el $\mathrm{SAG}^{7}$. En ese contexto ONGs, las asociadas a una Red Social, "Grito das Aguas" y organizaciones sociales con presencia en la región de la Tres Fronteras sostienen que el proyecto controlado por el Banco Mundial, en realidad busca información estratégica para las grandes corporaciones que orientan sus inversiones hacia el mercado del agua y pretenden el control privado de nuestros recursos ambientales (Fogel, 2006). El hecho que la Organización de Estados Americanos sea parte del estudio llevó a Aurelio García, del Brasil, a afirmar que Estados Unidos puso al Banco Mundial y a la OEA al frente de un proyecto que busca controlar el acuífero.

Los componentes del proyecto implementado por el Banco Mundial comprenden $^{8}$ :

7 El 22 de mayo de 2003 se reunieron en Montevideo el BM y los países que integran el MERCOSUR. Allí se firmó el proyecto de Protección Ambiental y Desarrollo Sustentable del Sistema Acuífero Guaraní. Un proyecto financiado por ese "organismo internacional", los Gobiernos de Holanda (Bank Netherlands Water Partnership Program - BNWPP) y Alemania (German Geological Survey - BGR), la Agencia Internacional de Energía Atómica y la Organización de Estados Americanos - OEA (con sede en Washington).

8 Según el News Release del BM (No. 2003/371_LAC), “Los \$27.24 millones del Proyecto del Sistema Acuífero Guaraní, que incluyen una donación del Fondo Mundial para la Naturaleza (Gef, por sus siglas en inglés) de \$13.4 millones, servirán para elaborar e implementar en forma conjunta un marco institucional y técnico para el manejo y la preservación del Acuífero." Una reserva de agua que puntualmente es reconocida por el Banco en ese mismo documento como:"un recurso estratégico de agua potable en el Cono Sur." 
1 Expansión y consolidación de la base actual del conocimiento científico y técnico acerca del SAG;

2 Desarrollo e instrumentación conjunta de un marco de gestión para el SAG, basado en un Programa Estratégico de Acción acordado;

3 Fomento a la participación pública y de los actores interesados, a la comunicación social y a la educación ambiental.

4 Evaluación y seguimiento del proyecto y diseminación de sus resultados;

5 Desarrollo de medidas para la gestión de las aguas subterráneas y para la mitigación de daños, de acuerdo con las características de la región, en áreas críticas

6 Consideración del potencial para la utilización de la energía geotérmica "limpia" del SAG

7 Coordinación y gestión del proyecto.

El estudio en curso comprende exploraciones de toda la cuenca, incluyendo ríos y arroyos, lagunas y esteros, cuyo epicentro se encuentra entre el Itaberá y la Triple Frontera. La insistencia del Departamento de Estado en las actividades ilícitas que se desarrollan en las Tres Fronteras y su conexión con el terrorismo internacional coincide con estos intereses del poder global y debe analizarse en ese marco; la representación de la amenaza del terrorismo y la respuesta a nivel militar resulta consistente con la necesidad de dificultar el MERCOSUR y buscar el control de los recursos naturales considerados estratégicos.

En este punto resaltan las representaciones acerca de la Región de la Triple Frontera de actores extra regionales, corporizados en el Departamento de Estado norteamericano, que combina su visión de seguridad de cara al eje del mal, con su percepción de los recursos estratégicos cualquiera sea su ubicación como estrechamente ligados al interés norteamericano. En la medida que esas 
representaciones no sean rechazadas las mismas podrían orientar la apropiación efectiva, ya en su alcance material, de los recursos del territorio.

Con la reiterada preocupación del Departamento de Estado por las Tres Fronteras el alcance de los conflictos potenciales se amplia; la colisión se da entre, por una parte países de la región con más intereses afines que contrapuestos, y por otra Estados Unidos, con afinidad de intereses confinada al plano retórico. La inquietud generada en el MERCOSUR, es tal que fue tema de análisis de la Cumbre de Córdoba, y Carlos Chaco Álvarez el Ejecutivo de la Comisión Permanente ha indicado "No queremos tener instalada en la Triple Frontera una fuerza de intervención" ${ }^{\prime \prime}$. Parece claro que la conexión de las actividades de las Tres Fronteras con el terrorismo internacional, que se plantea desde los Estados Unidos, no solo responde a la búsqueda de nuevos enemigos luego del colapso del socialismo real, sino también a la pretensión de controlar recursos estratégicos.

En este caso el conflicto, y la amenaza de intervención de los Estados Unidos, se constituye en un factor de integración política efectiva entre los países de la región, al generar posturas de rechazo de aquella amenaza, tanto a nivel de gobiernos como de organizaciones y movimientos sociales. Esta experiencia demuestra que si el territorio de frontera es construido y controlado solo por los actores que manejan más recursos, y la soberanía de los países se debilitara, el control de la región puede pasar a la potencia extraterritorial. En esfuerzos por evitar esa lógica el Gobierno de Paraguay anunció recientemente a los Estados Unidos su decisión de no renovar su acuerdo para otorgar inmunidad a sus efectivos militares, demostrando su interés en navegar la globalización, y no solo sufrir sus consecuencias negativas. Este es otro ejemplo de intereses comunes, y una realidad económica y política del mundo, que nos plantean como imperativo unirnos para tener

9 Véase abc 20/07/2006. 
voz y hacer respetar nuestros derechos soberanos, en una época de transición, de gestación de un nuevo orden internacional.

\section{El control de la biodiversidad}

Otro proceso relevante en el lado paraguayo de la Región de las Tres Fronteras es el control de la biodiversidad. Recientemente la Ley 3003/06 establece un Fondo Ambiental, en el marco de un acuerdo de canje de naturaleza por deuda con el Gobierno de los Estados Unidos, destinado a la protección de la biodiversidad en Áreas Protegidas del Bosque Atlántico Interior. Lo sugestivo es que el Fondo es manejado por un Consejo con siete miembros, de los cuales cinco representan a ONGs ambientalistas, entre las cuales predominan las ONGs transnacionales, que se asume representan a la sociedad civil, encarnando sus virtudes y no sus vicios.

Estos acuerdos recientes parecen apuntar al control de los recursos genéticos, de la biodiversidad, por parte de las grandes corporaciones, pero los escenarios que se pueden construir son inciertos. Si asumiéramos que estamos en un mundo unipolar con la conducción norteamericana la biodiversidad del Bosque Atlántico Interior ya no serán de nuestros pueblos; en cambio si entendemos que existen nuevos espacios ampliados en la política y en la economía, podemos proteger nuestra biodiversidad.

\section{A modo de conclusión}

La Región de Tres Fronteras constituye ciertamente un laboratorio privilegiado para estudiar problemas y oportunidades para la integración, en un contexto de búsqueda incierta de un nuevo orden internacional, que entendemos será multipolar y no dejará espacio para estrategias nacionales aisladas.

Los procesos reseñados ofrecen oportunidades para profundizar la integración, que debe extenderse a espacios más amplios que el 
MERCOSUR, Ilegando a la Comunidad Sudamericana de Naciones, aunque solo sea por responder a una demanda imperativa de la realidad económica y política del mundo de hoy. Sin embargo así como se observan los problemas que dificultan en la región los procesos de integración más allá de los países que comparten la región de la triple frontera (papeleras, Petrobras en Bolivia, entredicho Venezuela - Perú, etc.), en nuestro caso también se desarrollan procesos con componentes negativos, que deberíamos encarar; en el sector paraguayo resalta la polarización social resultante de la expansión de la soja transgénica que resulta, en una suerte de despropósito, de los intercambios fronterizos.

En la lógica del repliegue en el territorio de la región como respuesta a la expansión de los sojeros brasileños que caracteriza a los grupos dominantes del Paraguay estaría pesando la misma representación del territorio regional de las clases dominantes que ya se expresó a fines del siglo XIX por una parte con la venta de las tierras públicas a empresas ligadas al capital extranjero, y por otra con la exaltación de las supuestas bondades de los enclaves forestales y yerbateros que operaron en la región; esas representaciones ciertamente se caracterizan por su tenacidad y operan como prisiones de larga duración. Esta orientación al repliegue sin embargo no es la misma a la de los campesinos paraguayos que hoy se movilizan para recuperar sus territorios.

Esa polarizada estructura social está aumentando la brecha entre los muy pobres y los prósperos empresarios, aunque la resistencia de los actores populares de los tres países, a este modelo que produce exclusión, constituye el aspecto positivo, ya que permite avizorar una integración entre nuestros pueblos.

No sólo entre Cuidad del Este y Foz de Yguazú la actividad comercial no es la más promisoria para la integración, y en esa medida habrá que buscar otros componentes en la política y en la economía, que complementen a las dos ciudades, sin olvidar que los proyectos de integración social constituyen la respuesta adecuada a la exclusión. 
La identificación, por parte del Consejo Nacional de Seguridad de los Estados Unidos, de un enemigo no Estatal, los supuestos fundamentalistas árabes de Cuidad del Este, genera un pretexto para la presencia militar norteamericana, y la respuesta común de los países del MERCOSUR constituye un avance en la construcción de ese espacio de integración que refuerza la idea de que tenemos una agenda común.

Los procesos de las Tres Fronteras nos muestra que la región está todavía en proceso de construcción, que requiere aporte de los distintos actores involucrados, que desde luego incluye a las Universidades, que deben responder a la necesidad creciente de alimentar con un pensamiento propio ilustrado la discusión pública sobre la agenda común.

\title{
The Triple Frontier Region: territories of integration and disintegration
}

\begin{abstract}
This article analyses the triple frontier (Foz do Iguaçú, Puerto Iguazu and Ciudad del Este) as a constructed territory, owned and controlled by actors, some of them extra-regional. These actors maintain between themselves ties that imply relations of power, and they are involved in activities and processes that have an effect on regional integration.
\end{abstract}

Keywords: Triple Frontier. Territory. Regional Integration.

\section{Referencias}

ALBíNZANO, Roberto Carlos. Antropología de los Procesos Fronterizos: conocer y actuar en la región de fronteras" en Cuadernos de la Frontera. Año I, № I. Posadas, 2004a. 
ALBÍNZANO, Roberto Carlos. El frente extractivista: una formación socioeconómica y espacial transfronteriza (Argentina, Brasil y Paraguay 1865-1930)" en Cuadernos de la Frontera. Año I, № II. Posadas, 2004b.

ALBíNZANO, Roberto Carlos. "Procesos transfronterizos complejos: el caso de la Triple Frontera" en Cuadernos de la Frontera. Año I, № III. Posadas, 2004c.

ANA (Agência Nacional de Águas) Proyecto para la protección Ambiental y Desarrollo Sostenible del Sistema Acuífero Guaraní. Brasilia, 2003, en http:// www.aquiferoguarani.hpg.ig.com.br

CECEÑA, Ana Esther. Paraguay, el eje de la dominación del Cono Sur. Buenos Aires, 2005.

FOGEL, Ramón y Marcial Riquelme (Comp). Enclave Sojero, merma de soberanía y pobreza. CERI, Asunción, 2005.

FOGEL, Ramón. La Ciencia y la Tecnología en Paraguay. CERI, Asunción, 2001.

FOGEL, Ramón. La cuestión socioambiental en el Paraguay. CERI, Asunción, 2006.

GIMÉNEZ, Gilberto y HÉAU, Catherine. El Desierto como territorio, paisaje e identidad cultural, en Culturales. Mexicoli.México, 2007.

SADER, Emir (Coord). Enciclopedia contemporánea de América Latina. Boitempo Editorial, Río de Janeiro, 2006.

SOUCHARD, Sylvain. Pionniers Brésiliens au Paraguay. Editions Karthala. Paris, 2002. 